\title{
Efficiency of Banks in Uzbekistan: A DEA Approach
}

\author{
Sherzod Khannaev \\ Department of Investments, Banking and Finance Academy of the Republic of Uzbekistan, 16 \\ Movarounnahr street, Tashkent, 100000, Uzbekistan
}

\begin{abstract}
In this paper we analyze cost efficiency of Uzbek banks between 2013 and 2018 by using Data Envelopment Analysis (DEA) under the constant-return-to-scale and variable-return-to-scale assumptions. We find that cost efficiency of Uzbek banks on average is increasing. We also find that banks that directly or indirectly state-owned are on average most efficient and private banks are least efficient.
\end{abstract}

Keywords: cost efficiency, constant-return-to-scale, variable-return-to-scale, ownership structure, data envelopment analysis

DOI: $10.7176 / \mathrm{EJBM} / 12-9-03$

Publication date:March $31^{\text {st }} 2020$

\section{Introduction}

Achieving cost efficiency is one of the most important issue for banks. High cost efficiency not only helps banks to gain competitive advantage in the banking market but it also promotes efficient recourse allocation in the society. In addition, efficient banks support the effectiveness of economic reforms. This in turn will lead to economic growth and overall prosperity. That is why governments strive to improve the efficiency of commercial banks using various political and economic tools.

To ensure stability of banking system government injected capital into state-owned banks several times since global financial crisis. Currently, the state's share in the Uzbek banks has risen to $86 \%$, and this has led to a significant reduction of the private sector's share in the banking sector. One of the main objectives of the banking system reforms which is accelerated after President Sh.Mirziyoev came to the power in 2016, is to improve the efficiency of banks by reducing share of the state in the banking sector and liberalizing financial market.

In this paper we analyse cost efficiency of Uzbek banks using Data Envelopment Analysis (DEA). DEA methodology is widely applied to analyse relative efficiency of banks. By determining efficient banks on the frontier it allows us to use multiple inputs and multiple outputs to compare relative efficiency of banks. One of the main advantage of DEA methodology compared to other econometric frontier techniques is that it is deterministic and non-parametric method. Thus, it does not require a priori assumptions about the analytical form of the production function and, therefore, there is no misspecification of the production technology. The disadvantage of the method is that results are sensitive to the outliers and possible mismeasurement problems.

We measure the relative efficiency of Uzbek banks according to their ownership structure in the period from 2013 until 2018. In order to analyse the efficiency of banks by their ownership structure, we have divided banks into four groups based on their ownership. We have divided state-owned banks into two groups. First, directly state-owned banks where the share of the state is $100 \%$ and state owns shares of these banks directly by the Ministry of Finance of the Republic of Uzbekistan (MFRU) and the Fund for Reconstruction and Development of the Republic of Uzbekistan (FRDRU). There are three such banks: "Milliy bank", "Xalq bank" and "Asaka bank". Second, indirectly state-owned banks where the share of the state is less than $100 \%$ or the state owns them through government bodies other than MFRU and FRDRU. We have divided the rest of the banks by their ownership into private and foreign banks.

\section{Literature review}

Nonparametric approach of measuring efficiency was introduced by Farrell (1957). However, his study was limited to the production of a single product, which was not suitable for evaluating efficiency of multiple outputs. Also, his idea of using mathematical programming to measure efficiency was unable to attract attention until the work of Charnes et al., (1978). In their research, they develop a mathematical programming algorithm that evaluates the activity of a set of homogenous structures known as decision-making units (DMUs) that produce multiple outputs from multiple inputs. This nonparametric method of evaluating performance is known as data envelopment analysis (DEA). According to the algorithm of the method, first of all, the empirical production frontiers are constructed and then the firms far from the frontier are considered ineffective.

Influence of commercial banks on the form of ownership is one of the most important tools for their efficiency. Governments try to use state-owned banks to finance socially important and not profitable projects for the private sector. Although there is an opinion that state banks play an important role in financing strategically and socially significant projects, because of their ineffectiveness, social interests remain out of the question because of their ineffectiveness (Boycko \& Shleifer, 1995; Cornett, Guo, Khaksari, \& Tehranian, 2010; Dewenter \& Malatesta, 
2001). In addition, corruption and increased government interference in the banking system lead to the widening of the gap between banks of other types of ownership and the efficiency of state banks (Burki \& Ahmad, 2010; Caprio \& Cull, 2000; Fries \& Taci, 2005; Lin \& Zhang, 2009).

The impact of financial liberalization in Turkey on the technological efficiency of Turkish commercial banks was analysed by Zaim (1995) using a nonparametric method. According to the analysis, technological efficiency of banks increased by $10 \%$ on average due to financial liberalization.

Although the state's share in the banking sector has been increasing steadily, both in formal and informal forms, the extent to which banks operate efficiently by ownership is poorly understood by scientists. Two scientific articles published so far have quantitatively analysed the efficiency of domestic banks. The analysis by Nigmonov (2010) used the DEA method for assessing banks' performance. The study covered 2004-2006 years and, according to the results, the average efficiency in all banks during the period being analysed has declined. Also, there is no empirically proven difference in the efficiency of banks with different forms of ownership. However, there are differences in efficiency by the size of banks.

\section{Methodology and variables}

DEA is a non-parametric methodology to determine the relative efficiency of production frontier based on the same multiple input and multiple output of DMUs. DEA constructs efficient frontier and identifies relatively efficient DMUs from the set of available data. DMUs that are below the frontier are considered as an inefficient DMU. Distance from interior points to the frontier is a scale of the particular DMU's inefficiency.

There are a number of DEA models. The most widely used ones are CCR-model (Charnes, Cooper, Rhodes, 1978) and the BCC-model (Banker, Charnes, \& Cooper, 1984). The main difference between these models is the way they treat returns-to-scale. While CCR is based on constant-return-to-scale assumption, BCC assumes that each DMU operates under the variable-return-to-scale.

\subsection{CCR-model}

In this method a measure of efficiency for each DMU is evaluated as a maximum ratio of weighted outputs to weighted inputs. To determine the weights for the ratio a restriction is imposed. According to the restriction, every DMU's similar ratio must be less than or equal to unity. By this restriction it is possible to reduce multiple inputs and outputs to a single "virtual" input and single "virtual" output without requiring preassigned weights. Then the efficiency measure can be evaluated using weights of the single "virtual" input-output combination. Formally the efficiency measure for DMU can be evaluated by using the following mathematical programming model:

$$
\min _{\lambda} z_{0}=\Theta_{0}
$$

subject to

$$
\begin{gathered}
\sum_{j=1}^{n} \lambda_{j} y_{r j} \geq y_{r^{0}}, \text { 茂 }=1,2, \ldots, s \\
\Theta_{0} x_{i^{0}}-\sum_{j=1}^{n} \lambda_{j} x_{i j} \geq 0, i=1,2, \ldots, m \\
\chi_{j} \geq, \text { 侥 }=1,2, \ldots, n
\end{gathered}
$$

This linear problem yields the optimal solution $\Theta^{*}$, which is the CCR-efficiency score for the particular DMU. By repeating this exercise for each DMU one can obtain efficiency score for each of them. The value of $\Theta$ is always less than or equal to one. If virtual input-output combination points of DMUs lay on the frontier then these DMUs are relatively efficient and $\Theta^{*}=1$. On the other hand, if $\Theta^{*}<1$ then it mean that these DMUs are relatively inefficient.

\subsection{BCC-model}

Since there are no constraints for the weights $\lambda_{\mathrm{j}}$, other than the positivity conditions in the problem (1)-(4), it implies constant return-to-scale. To allow for variable-return-to-scale, it is necessary to add a convexity condition for $\lambda_{\mathrm{j}} \lambda_{j}$, i.e. to include in the model (1)-(4) the constraint:

$$
\sum_{j=1}^{n} \lambda_{j}=1 .
$$

The resulting DEA model is called the BCC-model. The input-oriented BCC-model for the DMU can be written formally as:

$$
\min _{\lambda} z_{0}=\Theta_{0}
$$


subject to

$$
\begin{gathered}
\sum_{j=1}^{n} \lambda_{j} y_{r j} \geq y_{r^{0}}, \text { 战 }=1,2, \ldots, s \\
\Theta_{0} x_{i^{0}}-\sum_{j=1}^{n} \lambda_{j} x_{i j} \geq 0, i=1,2, \ldots, m \\
\sum_{j=1}^{n} \lambda_{j}=1 . \\
\lambda_{j} \geq 0, \text { 侥 }=1,2, \ldots, n
\end{gathered}
$$

Solving the model for each DMU, the BCC-efficiency scores are obtained, with a similar interpretation for its values as in the CCR model. These scores are also called "pure technical efficiency scores", since they are obtained from a model that allows variable-returns-to-scale and hence eliminates the "scale part" from the analysis. Generally, for each DMU the CCR-efficiency score will not exceed the BCC-efficiency score. The reason is BCCmodel evaluated efficiency "locally" rather than "globally".

\subsection{Variables and descriptive statistics}

The following variables are taken as inputs and outputs. Outputs such as bank products and services consist of the total loans issued to clients $\left(y_{1}\right)$, other earning assets $\left(y_{2}\right)$ and non-interest income $\left(y_{3}\right)$. As inputs total liabilities $\left(x_{1}\right)$, the fixed assets $\left(x_{2}\right)$ and labor cost $\left(x_{3}\right)$ are used. Price of inputs also has divided into three types: cost of attracted funds $\left(w_{1}\right)$ - ratio of total interest expense to total liabilities, cost of fixed asset $\left(w_{2}\right)$ - ratio of other operating expenses to total fixed assets, and ratio of labor cost to total assets used as a proxy for wage $\left(w_{3}\right)$.

Statistical data has collected from both end-of-year balance sheets and income statements of Uzbek commercial banks. The observations are based on unbalanced statistical data of banks operating in the Uzbek banking market from 2013 to 2018. The following table presents the descriptive statistics of the variables.

Table 1. Descriptive statistics

\begin{tabular}{cccccc}
\hline \hline Variables & Observation & Mean & Std.dev. & Minimum & Maximum \\
\hline $\mathrm{y}_{1}$ & 151 & 2462545 & 4852895 & 358 & 33300527 \\
$\mathrm{y}_{2}$ & 151 & 28970 & 92124 & 0 & 1020231 \\
$\mathrm{y}_{3}$ & 151 & 94832 & 121943 & 138 & 766479 \\
$\mathrm{x}_{1}$ & 151 & 3159565 & 5595670 & 12494 & 37104642 \\
$\mathrm{x}_{2}$ & 151 & 89898 & 140417 & 325 & 1141712 \\
$\mathrm{x}_{3}$ & 151 & 63724 & 63855 & 716 & 311188 \\
$\mathrm{~W}_{1}$ & 151 & 0.036 & 0.033 & 0.000 & 0.349 \\
$\mathrm{w}_{2}$ & 151 & 0.849 & 0.462 & 0.191 & 2.784 \\
$\mathrm{~W}_{3}$ & 151 & 0.029 & 0.015 & 0.004 & 0.071 \\
\hline \hline
\end{tabular}

\section{Results}

The summary results for CCR model are presented in Table 2. In the table, mean efficiency M stands for the average of all optimal values $\Theta^{*}$ obtained by CCR model for each bank.

Table 2. Summary results (CCR model)

\begin{tabular}{crrrrrr}
\hline & 2013 & 2014 & 2015 & 2016 & 2017 & 2018 \\
\hline Number of DMUs & 26 & 26 & 26 & 26 & 27 & 27 \\
Average efficiency (M) & 0.35 & 0.40 & 0.38 & 0.41 & 0.40 & 0.46 \\
Standard deviation (s) & 0.19 & 0.20 & 0.16 & 0.20 & 0.22 & 0.19 \\
Average inefficiency = ((1-M)/M) & 1.85 & 1.52 & 1.65 & 1.42 & 1.50 & 1.19 \\
Interval I = [M-s; M+s]: $\quad[0.16 ; 0.54][0.20 ; 0.59][0.21 ; 0.54][0.21 ; 0.62][0.18 ; 0.62][0.27 ; 0.64]$ \\
\% of DMUs in Interval I & $81 \%$ & $81 \%$ & $73 \%$ & $81 \%$ & $70 \%$ & $67 \%$ \\
Minimum & 0.02 & 0.12 & 0.02 & 0.02 & 0.04 & 0.07 \\
Maximum & 1.00 & 1.00 & 0.82 & 1.00 & 1.00 & 0.79 \\
\hline
\end{tabular}

Under the constant-return-to-scale assumption in 2013 the average efficiency of banks was only 0.35 , which means that the average bank, if producing its output on the efficiency frontier instead of at its current location, would have needed only $35 \%$ of the inputs currently being used. After $5 \%$ jump of average efficiency score of Uzbek banks in 2014 it was relatively stable until 2018. As Table 1 shows, in subsequent years the situation gradually changed. However, average bank still should decrease its cost around $50 \%$ to be on the efficient frontier. Large standard deviation, maximum and minimum values indicate that efficiency of Uzbek banks distributed 
unevenly. The percentage of banks whose efficiency falls within the interval of one standard deviation around the mean is narrowed to $68 \%$ from $81 \%$, which means that a number of extreme performers in terms of technical efficiency is increased.

If we allow for variable-return-to-scale, we find much higher average efficiency scores during the period being analysed. Allowing for variable-returns-to-scale always results in a higher average efficiency because DMUs that were efficient under the constant-returns-to-scale are accompanied by new efficient DMUs that might operate under the increasing or decreasing returns-to-scale. Allowing for variable-returns-to-scale reveals the impact of only a few relatively small banks that were spanning the production possibilities frontier under the CCR model.

Table 3. Summary results (BCC model)

\begin{tabular}{crrrrrr}
\hline & 2013 & 2014 & 2015 & 2016 & 2017 & 2018 \\
\hline Number of DMUs & 26 & 26 & 26 & 26 & 27 & 27 \\
Average efficiency (M) & 0.49 & 0.55 & 0.53 & 0.58 & 0.59 & 0.65 \\
Standard deviation (s) & 0.21 & 0.22 & 0.19 & 0.24 & 0.27 & 0.23 \\
Average inefficiency = ((1-M)/M) & 1.05 & 0.82 & 0.87 & 0.72 & 0.68 & 0.54 \\
Interval I = [M-s; M+s]: [0.28;0.69] $[0.33 ; 0.77][0.34 ; 0.73]$ & {$[0.34 ; 0.82][0.32 ; 0.87][0.42 ; 0.88]$} \\
\% of DMUs in Interval I & $73 \%$ & $65 \%$ & $62 \%$ & $65 \%$ & $56 \%$ & $67 \%$ \\
Minimum & 0.13 & 0.14 & 0.24 & 0.24 & 0.15 & 0.10 \\
Maximum & 1.00 & 1.00 & 1.00 & 1.00 & 1.00 & 1.00
\end{tabular}

Under both assumptions one can conclude that in the six-year period, average Uzbek bank has improved its efficiency score by moving toward efficient frontier. However, large standard deviation and decreasing percentage of banks that lie within one standard deviation around the mean indicate that as time passes difference of banks in terms of efficiency is widening. In fact, while a number of banks with relatively low efficiency is almost constant, a number of banks becoming efficient is increasing. However, there is negligible change in terms of number of banks and competition in the Uzbek banking market during period being analysed.

After evaluating cost efficiency of the Uzbek banking system, it is important to examine cost efficiency of banks based on their ownership structure. Table 4 shows cost efficiency based on ownership of banks under the constant and variable return-to-scale assumptions.

From the results in Table 4, we observe that cost efficiencies for constant and variable return-to-scale present mixed results in terms of rankings of banks with different ownership structure. According to CCR model, efficiency of banks other than foreign banks are less volatile and increasing. Results also show that public banks are more cost efficient on average compared to private banks. However, the average efficiency gap of these banks is narrowing as time passes. As private banks joint stock banks also have experienced steady and significant efficiency gain during the period of analysis.

According to BCC model, while public banks have had significant efficiency improvement on average during the period, foreign banks have gained least average. Average efficiency scores under variable-return-to-scale are greater than average efficiency scores under the constant-return-to-scale. This is due to the fact that the variablereturn-to-scale is more flexible and envelops the data tighter than the constant-return-to-scale.

From the efficiency scores of banks with different ownership structure, it can be concluded that banks in Uzbekistan are technically inefficient. High level of inefficiency of banks in Uzbekistan implies that there is a managerial failure to fully exploit resources available to them. It infers that bank managers must ensure that they fully utilize their inputs to generate a maximum level of output to be efficient.

Table 4. Average cost efficiencies based on ownership structure

\begin{tabular}{lcccc}
\hline \hline \multicolumn{5}{c}{ Part I. CCR model } \\
\hline Years & Public banks & Joint Stock banks & Private banks & Foreign banks \\
\hline 2013 & 0.40 & 0.39 & 0.24 & 0.42 \\
2014 & 0.37 & 0.42 & 0.30 & 0.52 \\
2015 & 0.44 & 0.42 & 0.36 & 0.29 \\
2016 & 0.68 & 0.44 & 0.36 & 0.30 \\
2017 & 0.57 & 0.44 & 0.32 & 0.36 \\
2018 & 0.48 & 0.52 & 0.43 & 0.35 \\
\hline \multicolumn{7}{r}{} & Part II. BCC model & & Foreign banks \\
\hline 2013 & Public banks & Joint Stock banks & Private banks & 0.58 \\
2014 & 0.57 & 0.55 & 0.31 & 0.62 \\
2015 & 0.63 & 0.60 & 0.41 & 0.51 \\
2016 & 0.64 & 0.59 & 0.44 & 0.53 \\
2017 & 0.79 & 0.65 & 0.44 & 0.62 \\
2018 & 1.00 & 0.63 & 0.41 & 0.61 \\
\hline \hline
\end{tabular}




\section{Conclusion}

We used DEA under the constant-return-to-scale and variable-return-to-scale assumptions to analyze cost efficiency of the banks in the Uzbek banking market in the period 2013-2018.

The analysis shows that on average cost efficiency of Uzbek banks has gradually increased in the period of being analyzed. Moreover, the number banks that lie on the efficiency frontier is also increased. In terms of ownership structure, while banks with direct or indirect state ownership have higher relative cost efficiency private banks are least efficient ones. This efficiency difference can be explained by state banks' access to cheap financial resources which are provided to finance some government projects.

\section{References}

Banker, R. D., Charnes, A., \& Cooper, W. W. (1984). Some models for estimating technical and scale inefficiencies in data envelopment analysis. Management Science, 30(9), 1078-1092.

Boycko, M., \& Shleifer, A. (1995). Next steps in privatization: Six major challenges. In Library of Congress Cataloging- in- Publication Data, Washington, DC (p. 87).

Burki, A. A., \& Ahmad, S. (2010). Bank governance changes in Pakistan: Is there a performance effect? Journal of Economics and Business, 62(2), 129-146.

Caprio, G., \& Cull, R. (2000). Bank privatization and regulation in Egypt. Egyptian Center for Economic Studies.

Charnes, A., Cooper, W. W., \& Rhodes, E. (1978). Measuring the efficiency of decision making units. European Journal of Operational Research, 2(6), 429-444.

Cornett, M. M., Guo, L., Khaksari, S., \& Tehranian, H. (2010). The impact of state ownership on performance differences in privately-owned versus state-owned banks: An international comparison. Journal of Financial Intermediation, 19(1), 74-94.

Dewenter, K. L., \& Malatesta, P. H. (2001). State-owned and privately owned firms: An empirical analysis of profitability, leverage, and labor intensity. American Economic Review, 91(1), 320-334.

Farrell, M. J. (1957). The measurement of productive efficiency. Journal of the Royal Statistical Society: Series A (General), 120(3), 253-281.

Fries, S., \& Taci, A. (2005). Cost efficiency of banks in transition: Evidence from 289 banks in 15 post-communist countries. Journal of Banking \& Finance, 29(1), 55-81. https://doi.org/10.1016/J.JBANKFIN.2004.06.016

Lin, X., \& Zhang, Y. (2009). Bank ownership reform and bank performance in China. Journal of Banking \& Finance, 33(1), 20-29.

Nigmonov, A. (2010). Bank performance and efficiency in Uzbekistan. Eurasian Journal of Business and Economics, 3(5), 1-25.

Zaim, O. (1995). The effect of financial liberalization on the efficiency of Turkish commercial banks. Applied Financial Economics, 5(4), 257-264. 